Cipango $\begin{aligned} & \text { Cipango } \\ & \text { Cahiers d'études japonaises }\end{aligned}$

$15 \mid 2008$

Guerre, colonialisme et commémoration

\title{
Nagai Kafū (1879-1959) et le champ littéraire : genèse d'un écrivain
}

\section{Tomomi Ōta}

\section{(2) OpenEdition}

1 Journals

\section{Édition électronique}

URL : https://journals.openedition.org/cipango/155

DOI : $10.4000 /$ cipango. 155

ISSN : 2260-7706

\section{Éditeur}

INALCO

\section{Édition imprimée}

Date de publication : 1 janvier 2008

Pagination : 282-285

ISBN : 978-2-85831-177-4

ISSN : $1164-5857$

\section{Référence électronique}

Tomomi Ōta, « Nagai Kafū (1879-1959) et le champ littéraire : genèse d'un écrivain », Cipango [En ligne], 15 | 2008, mis en ligne le 14 novembre 2011, consulté le 30 juin 2021. URL : http:// journals.openedition.org/cipango/155; DOI : https://doi.org/10.4000/cipango.155

Ce document a été généré automatiquement le 30 juin 2021.

\section{(c) (7) (8)}

Cipango est mis à disposition selon les termes de la Licence Creative Commons Attribution - Pas d'Utilisation Commerciale 4.0 International. 


\title{
Nagai Kafū (1879-1959) et le champ littéraire : genèse d'un écrivain
}

\author{
Tomomi Ōta
}

\section{RÉFÉRENCE}

Nagai Kafū (1879-1959) et le champ littéraire : genèse d'un écrivain, Thèse de doctorat soutenue par Ōta Tomomi (Paris 7-Diderot, 2008), sous la direction de C. Sakai.

1 Notre thèse porte sur les débuts de la carrière littéraire de l'écrivain Nagai Kafū 永井荷 風 entre 1898 et 1919. En 1898, Kafū commence son apprentissage en devenant le disciple de Hirotsu Ryūrō 広津柳浪, un écrivain connu de l'époque; en 1919, auteur installé, il a déjà vécu la moitié de son existence. Entre 1898 et 1912 se produisent des événements historiques importants, la Guerre russo-japonaise en 1904, l'annexion de la Corée par le Japon en 1910, et l'affaire de Haute Trahison en 1910-1911. La phase de modernisation et d'occidentalisation de la société japonaise, entamée dès le début de l'ère Meiji et qui s'intensifie alors, s'accompagne d'une répression accrue visant à faire taire toute voix dissonante. Néanmoins, la fin de l'ère Taishō se caractérise par le mouvement de la «démocratie de Taishō» concrétisé par le suffrage universel masculin promulgué en 1925.

2 Etudier la vie et l'œuvre de Kafū entre 1898 et 1919 nous permet d'observer comment la communauté des écrivains à l'intérieur de la société japonaise en pleine mutation se développe et se construit en un champ littéraire doté de différentes institutions et de positionnements variés, et comment un écrivain traverse cette période mouvementée du Japon moderne.

3 L'univers littéraire de Kafū subit les influences de la littérature japonaise de l'époque d'Edo et de l'ère Meiji, ainsi que celles de la littérature française, principalement du XIX siècle. Son écriture mélange le style de la langue classique et celui de la langue parlée de son temps. Ses réflexions sur la culture japonaise et les représentations qu'il se fait de l'Occident sont multiples et parfois incohérentes, voire contradictoires. L'œuvre de 
Kafū serait caractérisée par cet amalgame complexe d'éléments différents et hétérogènes aux niveaux des thèmes, des styles et des représentations employés.

Or cette construction protéiforme que nous observons dans ses textes littéraires est aussi caractéristique du processus de création des images et des postures que Kafū met en œuvre et parfait pour lui-même : "geijutsu-ka » (l'artiste sur le modèle occidental), «kichō-sha» (l'intellectuel de retour de l'étranger) et "gesaku-sha» (l'écrivain de divertissement de l'époque d'Edo). Sa vie en tant qu'écrivain est composée du chevauchement de différentes postures, d'images et d'attitudes, plutôt que de la progression linéaire d'une posture à l'autre.

5 Par ailleurs, il nous semble que la compréhension du point de vue de Kafū sur le monde qui l'entoure et sur lui-même peut permettre de mieux comprendre les différentes stratégies qu'il a suivies. En effet son ironie, son attitude critique et autocritique, ainsi que son refus du conformisme et des conventions, concourent au processus d'élaboration de ses postures qui se caractérisent toujours par un regard décalé sur le monde. Dans l'écart que ses postures créent par rapport à la société, Kafū trouve un espace d'où il peut s'exprimer librement.

6 Nous nous fondons sur une approche de type sociologique afin d'examiner les différents états du champ littéraire et la place qu'occupent les écrivains et les textes littéraires dans cette communauté pendant la période qui nous concerne, afin de saisir pleinement les stratégies et le sens de chaque posture de Kafū par rapport à d'autres positions d'écrivains. En relation avec cette étude du champ littéraire, nous définissons les diverses postures de Kafū par le biais des concepts d'ethos et de posture étudiés dans le domaine de l'analyse du discours. C'est cette analyse des dimensions discursive (textuelle) et non-discursive (contextuelle) de la posture de Kafū qui nous permet de saisir sa façon particulière d'occuper une position dans le champ littéraire. Complémentairement, les études post-coloniales, qui dévoilent le caractère construit des images de l'Orient des Occidentaux et de l'Occident des Orientaux, nous donnent une piste de réflexion pour souligner l'originalité des textes de Kafū, dans lequel le discours orientaliste, regard fantasmé des Occidentaux sur l'Orient, et le regard d'admiration de Kafū porté sur l'Occident se croisent et construisent un réseau d'images plurielles de l'Occident et de l'Orient. L'approche post-coloniale nous permet de saisir l'une de ses postures exemplaires, construite au niveau discursif autour d'un jeu complexe de représentations de l'Orient et de l'Occident.

7 La première période de Nagai Kafū montre le parcours typique d'un écrivain de sa génération sur le plan de l'apprentissage du métier et l'insertion dans le milieu littéraire par l'intermédiaire d'un maître, ainsi que les influences littéraires qui dominent à la fin $\mathrm{du} \mathrm{XIX}^{\mathrm{e}}$ siècle et au début du $\mathrm{XX}^{\mathrm{e}}$ à travers la relecture du patrimoine national et la découverte des œuvres occidentales. En ce sens, cette étude permet de mettre en évidence certaines caractéristiques du processus d'émergence de la littérature japonaise moderne.

8 Par ailleurs, cette période nous révèle la trajectoire originale d'un auteur. Le cas particulier de Kafū illustre ainsi l'une des possibilités pour un écrivain du début du Xx siècle au Japon de continuer à occuper une place importante dans le champ littéraire en renouvelant constamment son écriture. Kafū assume sa différence et sa position distincte par rapport à ses pairs, ce qui lui est tantôt bénéfique, tantôt désavantageux pour sa survie dans le milieu littéraire. L'originalité de Kafū réside aussi dans sa faculté 
d'aller au-delà de la copie du modèle, nécessaire au moment de l'apprentissage, et d'inventer son propre discours littéraire.

9 La présente thèse examine les premières œuvres de Kafū ainsi que les critiques et les témoignages concernant l'écrivain, afin de dégager un projet artistique global associant la création de nouveaux modèles à partir de diverses influences littéraires, anciennes et modernes, orientales et occidentales, à celle de postures homologues originales. Nous tentons ainsi de mettre en évidence deux paradigmes, la recherche de la liberté, et l'attitude ironique de Kafū, qui expliquent, selon nous, le caractère hybride de son œuvre. Nous développons notre réflexion sur la première période de Kafū en quatre parties.

Dans le chapitre 1, nous utilisons le concept de champ littéraire de Bourdieu afin d'analyser le développement historique de la communauté littéraire au Japon depuis l'ère Meiji jusqu'en 1903. Les positions des écrivains dans le champ littéraire et leurs interactions avec la position de Kafū sont étudiées afin d'éclairer son cheminement en tant que nouvel écrivain vers une reconnaissance littéraire pendant la période de 1898 à 1903, c'est-à-dire de son entrée en littérature à son départ aux Etats-Unis. En nous inspirant d'autres méthodologies, notamment celles de Dubois et de Maingueneau, nous examinons l'écriture ou le style de Kafū, les genres dans lesquels il s'essaie, les situations d'énonciation de ses œuvres et les thèmes traités dans ses textes littéraires du début.

11 Le chapitre 2 traite des œuvres créées pendant et juste après son séjour en Occident (1904-1911) et de la posture du geijutsu-ka (l'artiste sur le modèle européen) que Kafū commence à mettre en œuvre. Le processus de création de cette posture par Kafū est étudié à travers son œuvre romanesque, ses essais, et la réaction et la réception de la critique de l'époque, en recourant aux concepts d'ethos et de posture.

Dans le chapitre 3, l'originalité des représentations de l'Orient et de l'Occident chez Kafū, qui contribue à la construction de sa posture de kichō-sha (l'intellectuel de retour de l'étranger), est examinée dans ses œuvres de la période 1908-1911. La coexistence de diverses figures hétérogènes et contradictoires dans le discours littéraire de Kafū et son regard ironique et autocritique sont mis en évidence en utilisant l'approche postcoloniale, notamment les analyses des représentations de l'Orient et de l'Occident. Nous examinons la façon dont Kafū reçoit et intériorise le regard d'admiration des Occidentaux sur l'Orient, exprime son admiration de l'Occident et crée de nouveaux discours pour décrire le monde dans lequel il se trouve.

Dans le dernier chapitre, la posture de gesaku-sha de Kafū sur le modèle anachronique de l'écrivain de divertissement de l'époque d'Edo, et le sens d'une posture anachronique et achronique pendant la période cosmopolite de l'ère Taishō, sont analysés en proposant une interprétation nouvelle. A travers la question de la censure, traitée dans les chapitres 2 et 4 , nous montrons aussi les limites morales et sociales auxquelles Kafū s'est trouvé confronté et sa façon d'exploiter ce problème pour la construction de sa posture tout en se préservant un espace de liberté indispensable à sa survie en tant qu'écrivain.

14 Ainsi Nagai Kafū n'a cessé de chercher à se distinguer de ses pairs afin d'obtenir la reconnaissance au sein du champ littéraire. C'est cette élaboration d'une posture auctoriale originale qui lui a d'abord apporté le succès, mais suite au durcissement de la censure du gouvernement de Meiji, la recherche de la liberté d'expression s'est ajoutée à celle de l'originalité. Au fil de ces analyses, nous pensons avoir pu dégager le fil 
conducteur qui traverse l'univers littéraire de Kafū. La singularité de ses œuvres et de ses postures, mais aussi la forte personnalité de cet auteur, recèlent sans doute les clés de la création d'une œuvre impérissable. 